\title{
SISTEM MONITORING PH AIR PADA AQUAPONIK MENGGUNAKAN MIKROKONTROLER ARDUINO UNO
}

\author{
Yuri Rahmanto*,1), Arinda Rifaini' ${ }^{2}$, S. Samsugi'), Sampurna Dadi Riskiono ${ }^{4)}$ \\ ${ }^{1,2)}$ Program Studi Teknik Komputer, Fakultas Teknik dan Ilmu Komputer, Universitas Teknokrat Indonesia \\ Jl. ZA. Pagar Alam No.9 -11, Labuhan Ratu, Bandar Lampung, Indonesia 35132 \\ ${ }^{3,4)}$ Program Studi Teknik Elektro, Fakultas Teknik dan Ilmu Komputer, Universitas Teknokrat Indonesia \\ Jl. ZA. Pagar Alam No.9 -11, Labuhan Ratu, Bandar Lampung, Indonesia 35132 \\ Email: 'yurirahmanto@teknokrat.ac.id
}

\begin{abstract}
The number of modern agriculture (Aquaponics) is carried out by farmers from the upper middle class and from the lower classes who have limited land, besides not consuming a lot of space and time wasted, this method can also produce maximum yields, by providing proper care. by monitoring the $\mathrm{pH}$ of water it is very important to know whether the quality is good or bad. Clean water with poor quality can have a bad impact on the health of plants and fish, namely the emergency of various diseases. Changes in the $\mathrm{pH}$ of water can also cause changes in smell, taste and color in water. This research aims to design and implement a series that functions to monitor pH levels in water by utilizing current technological developments. with the Arduino Uno sensor and microcontroller type can make it easier to use automatic monitoring tools. Microcontroller Measurement of the $\mathrm{pH}$ of water can be done using a pH meter manually, then made monitoring system to facilitate $\mathrm{pH}$ control so that the process of plant maintenance becomes better and easier.
\end{abstract}

Keywords: microcontroller, monitoring, Temperature sensor, mustard, pH sensor

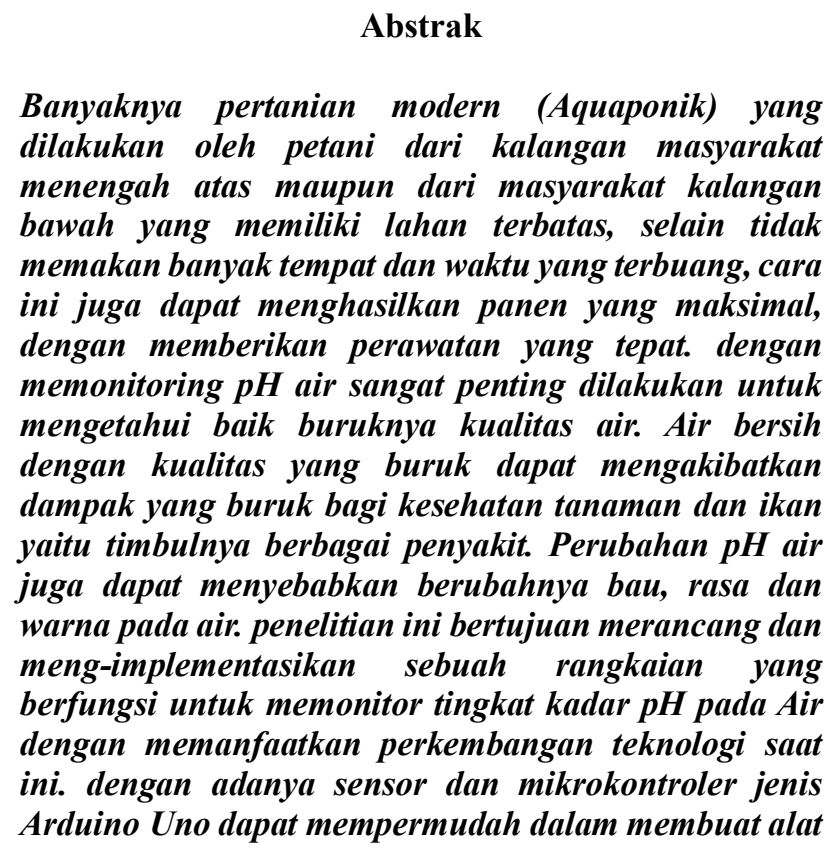

Monitoring otomatis. Mikrokontroler Pengukuran pH air dapat dilakukan dengan menggunakan $\mathrm{pH}$ meter dengan cara manual, maka dibuatlah sistem monitoring untuk memudahkan control $\mathrm{pH}$ air sehingga proses perawatan tanaman menjadi lebih baik dan mudah.

Kata Kunci: mikrokontroler, monitoring, sensor suhu, sawi, sensor $p H$

\section{Pendahuluan}

Perkembangan populasi manusia di perkotaan semakin pesat sehingga berdampak pada lahan pemukiman yang semakin sempit. hal ini juga berdampak pada suhu udara yang semakin tinggi karena tumbuhan sebagai penghasil oksigen jarang dijumpai. Sebagian besar dari masyarakat Indonesia berasumsi bahwa lahan yang sempit tidak akan dapat dimanfaat, khususnya sebagai lahan pertanian [1].

Dengan adanya beraneka ragam metode pertanian yang dikembangkan salah satunya adalah metode cocok tanam dengan sistem Aquaponik lahan yang sempit tersebut dapat dimanfaatkan secara maksimal. Sistem ini merupakan kombinasi antara akuakultur dengan hidroponik yang menghasilkan simbiosis mutualisme atau saling menguntungkan. Akuakultur merupakan budidaya ikan, sedangkan hidroponik adalah budidaya tanaman tanpa tanah yang berarti budidaya tanaman yang memanfaatkan air dan tanpa menggunakan tanah sebagai media tanam atau soilles. Aquaponik memanfaatkan secara terus menerus air dari pemeliharaan ikan ke tanaman dan selanjutnya dikembalikan lagi ke kolam ikan. Inti dasar dari sistem ini adalah penyediaan air yang optimum untuk masing-masing komoditas dengan memanfaatkan sistem re-sirkulasi sehingga dapat mempermudah pekerjaan manusia dengan memanfaatkan kemajuan teknologi [2][3].

Secara umum, Aquaponik menggunakan sistem resirkulasi, artinya memanfaatkan kembali air yang telah digunakan dalam budidaya ikan dengan filter biologi dan fisika berupa tanaman dan medianya. Resirkulasi yang digunakan berisi kompartemen pemeliharaan dan kompartemen pengolahan air. Penggunaan bahan-bahan filter, misalnya batu zeolit, clay, hidroton, kerikil atau pasir sebagai substrat bakteri yang mampu mengatasi dan mengatur kelebihan senyawa - senyawa nitrogen berbahaya untuk ikan pada sistem Aquaponik. Dengan 
demikian, tanaman berfungsi sebagai biofilter untuk menyerap amonia, nitrat, nitrit, dan fosfor yang berbahaya untuk ikan, jadi air yang bersih kemudian dapat dialirkan kembali ke bak ikan. Biasanya, sistem pengolahan air tersusun atas kompartemen, dekantasi, kompartemen filtrasi, kompartemen oksigenasi dan kompartemen strerilisasi [4].

Monitoring $\mathrm{pH}$ air sangat penting dilakukan untuk mengetahui baik buruknya kualitas air. Penyediaan air bersih dengan kualitas yang buruk dapat mengakibatkan dampak yang buruk bagi kesehatan tanaman dan ikan yaitu timbulnya berbagai penyakit. Perubahan $\mathrm{pH}$ air juga dapat menyebabkan berubahnya bau, rasa dan warna pada air. Berdasarkan Peraturan Menteri Kesehatan (PERMENKES) nomor 416 tahun 1990 tentang syaratsyarat dan pengawasan kualitas air bahwa standar kualitas air bersih yang baik yaitu memiliki kadar $\mathrm{pH}$ 6,5 sampai 9,0 [5]. Pengukuran $\mathrm{pH}$ air dapat dilakukan dengan menggunakan $\mathrm{pH}$ meter, cara ini hanya bisa dilakukan secara manual maka dibuatlah "SISTEM MONITORING pH AIR BERBASIS MIKROKONTROLLER ARDUINO UNO R3" untuk memudahkan control pH air sehingga proses perawatan tanaman dan kolam menjadi lebih baik dan mudah.

\section{Metode Penelitian}

Metodologi penelitian dilakukan secara terstruktur dengan melakukan Analisa permasalahan terlebih dahulu, Studi Literatur, Mengalisa kebutuhan, Melakukan perancangan sistem, Implementasi serta Uji coba dan indentifikasi kesalahan. Analisa permasalahan yaitu dengan memahami beberapa elemen dalam berbagai situasi dalam permasalahan yang ada kemudian mencari solusi peyelesaiannya [6][7].

Analisa Kebutuhan yaitu menganalisa alat dan bahan yang dibutuhkan dalam peyelesaian masalah, termasuk kebutuhan alat dan bahan, Dalam pembuatan alat tugas akhir ini memerlukan beberapa komponen dan bahan. Komponen dari bahan yang digunakan dalam pembuatan penelitian ini adalah :

1. Komputer/Laptop

Digunakan untuk membuat sebuah program, compiler program, dan mengupload program ke dalam Mikrokontroller.

2. Solder

Digunakan untuk menyolder Terminal (kaki) komponen elektronika sehingga menyatu dengan Papan Rangkaian (PCB) dengan menggunakan timah yang dipanaskan atau sering disebut dengan Proses Menyolder (Soldering Process).

3. Mesin bor

Digunakan untuk membuat lubang-lubang pada pipa

4. Lem kaca

Digunakan untuk mengelem kaca aquarium

5. Gergaji besi

Digunakan untuk memotong pipa

Bahan-bahan yang dibutuhkan dalam pembuatan

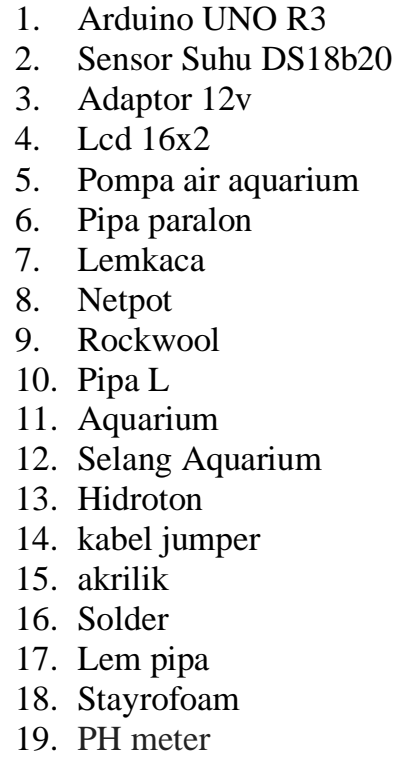

Perancangan Sistem yaitu suatu metode awal dalam pembuatan sebuah alat yang sangat penting karena tanpa sebuah perancangan alat yang dibuat tidak dapat berjalan dengan maksimal. untuk memperoleh hasil yang maksimal diperlukan rancangan yang baik dengan memperhatikan sifat dan karakteristik dari tiap-tiap komponent yang digunakan, agar kerusakan komponen dapat dihindari. dalam tahap perancangan terdiri dari beberapa tahapan yaitu perancangan blok diagram, diagram alir atau flow chart, alat dan bahan, hingga pada perancangan keseluruhan alat.

Perancangan memerlukan suatu ketelitian, keuletan dan ketepatan karena perancangan awal akan menentukan akhir dari suatu perancangan dalam proses pembuatan alat. Jika perancangan awal salah maka hasil akhirnya akan salah. Proses perancangan sangat diperlukan dalam proses pembuatan alat, khususnya perancangan alat elektronika. Tujuan proses perancangan alat adalah Agar alat yang dihasilkan akan sesuai dengan yang diharapkan, untuk memilih komponen-komponen yang paling tepat, ntuk menentukan kesalahan-kesalahan atau kendala eror yang terjadi, Meminimalis biaya namun dengan alat yang hasilnya memuaskan.

a. Diagram Blok

Pada gambar diagram blok di bawah ini menjelaskan tentang cara kerja alat secara keseluruhan mulai dari input, proses, hingga output. Dalam diagram blok ini hanya terdapat hubungan jalur antara blok-blok saja, tetapi tiap masing-masing blok terdapat komponen utama dan komponen pendukung. Pada gambar di bawah ini adalah gambar diagram blok dari mikrokontroller alat ini. 


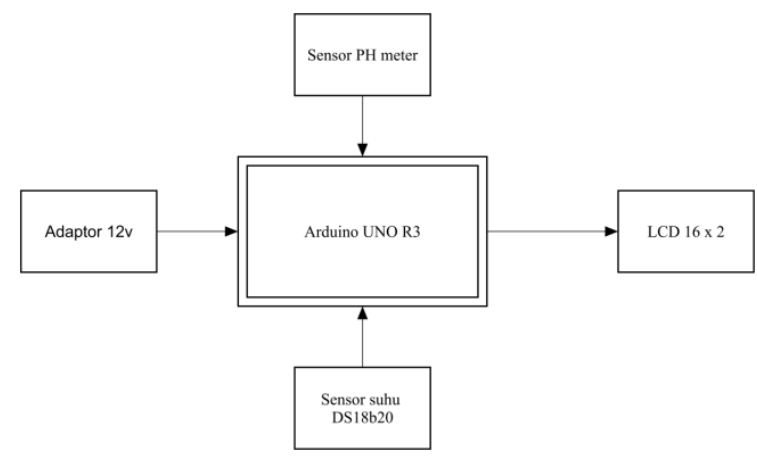

Gambar 1. Diagram Blok Cara Kerja Alat

Dari blok diagram di atas dapat dijelaskan fungsi masing-masing blok [8] sebagai berikut :

1. Adaptor $12 \mathrm{v}$ untuk memberikan tegangan pada arduino dan komponen lain nya yang terhubung

2. Mikrokontroller Arduino Uno R3 digunakan untuk mengontrol semua komponen baik itu komponen input dan komponen output [9].

3. Lcd 16x2 Karakter digunakan sebagai untuk monitor aktivitas apa yang sedang dilakuakan oleh sistem.

4. Sensor Suhu air digunakan untuk mengetahui nilai Suhu air.

5. Sensor $\mathrm{pH}$ air digunakan untuk mengetahui tingkat keasaman pada air.

\section{b. Diagram Alir}

Diagram alir adalah sebuah jenis diagram, Flowchart atau diagram alir adalah sebuah jenis diagram yang mewakili algoritme, alir kerja atau proses, yang menampilkan langkah-langkah dalam bentuk simbolsimbol grafis [10][11], Pada diagram alir di bawah ini menjelaskan tentang bagaimana cara kerja dan proses alat bekerja:

Penjelasan tentang Flowchart Sensor $\mathrm{pH}$ air :

1. Pada awal sistem mulai akan mempersiapkan semua komponen sistem seperti Sensor $\mathrm{pH}$ air, LCD, Dan komponen pendukung lainnya yang terhubung dalam satu kesatuan komponen.

2. Inputan berasal dari komponen Sensor $\mathrm{pH}$ air.

3. Selanjutnya Sensor $\mathrm{pH}$ air mengirim data berupa nilai $\mathrm{pH}$ air dan ke Arduino untuk di tampilkan di LCD.

Penjelasan tentang Flowchart Sensor Suhu :

1. Pada awal sistem mulai akan mempersiapkan semua komponen sistem seperti Sensor Suhu air, LCD, Dan komponen pendukung lainnya yang terhubung dalam satu kesatuan komponen.

2. Inputan berasal dari komponen Sensor Suhu air.

3. Selanjutnya Sensor Suhu air mengirim data berupa nilai $\mathrm{pH}$ air dan ke Arduino untuk di tampilkan di LCD.
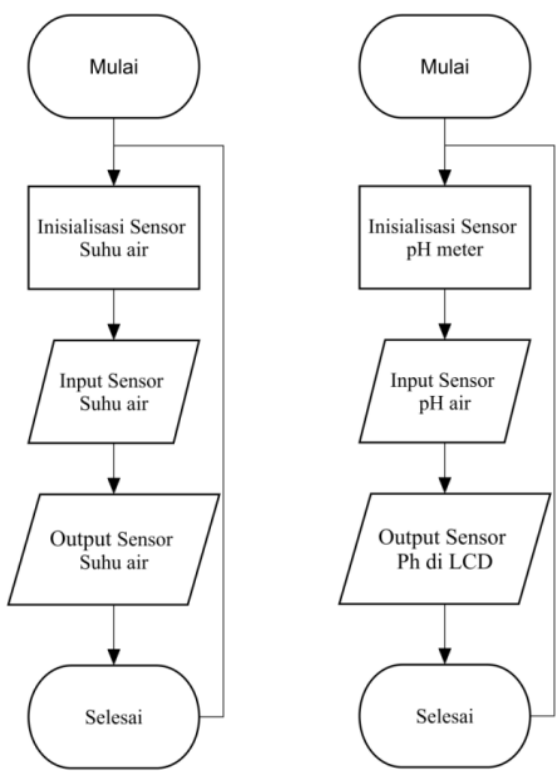

Gambar 2. Diagram Alir/Flowchart Sensor pH meter dan Sensor Suhu Air

c. Perancangan rangkaian keseluruhan

Perancangan rangkaian keseluruhan alat terdiri dari empat elemen penting yang saling terintegrasi. Elemenelemen penting tersebut yaitu rangkaian input, rangkaian pengendali, rangkaian output dan juga software program yang saling terintegrasikan.Rangkaian yang terdiri dari komponen-komponen elektronika baik berupa input atau output yang dibutuhkan oleh mikrokontroller agar dapat berfungsi dengan baik. Rangkaian keseluruhan alat dapat dilihat pada gambar berikut:

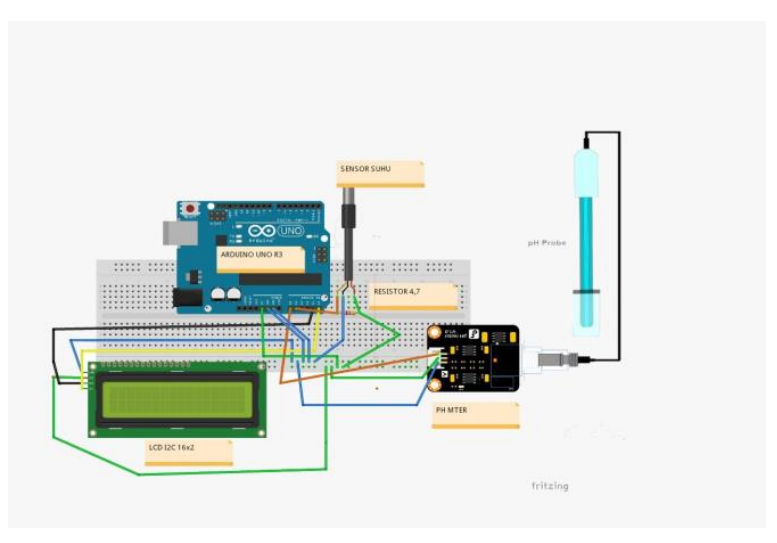

Gambar 3. Perancangan Keseluruhan Alat

Perancangan Sensor Suhu DS18b20, Sensor Suhu DS18B20 adalah sensor Suhu yang menggunakan interface one wire, sehingga hanya menggunakan kabel yang sedikit dalam instalasi nya. Unik nya sensor ini bisa di jadikan paralel dengan satu input. Arti nya kita bisa menggunakan sensor DS18B20 lebih dari satu namun output sensor nya hanya di hubungkan ke satu PIN Arduino. Alasan ini membuat sensor ini banyak di gunakan, apalagi sensor ini memiliki tipe waterprof, 
sehingga sensor ini bisa kita buat sebagai alat ukur dan kontrol pemanas air. Sedangkan Fungsi dari resistor ini adalah sebagai ,pullup ${ }^{\text {ee }}$ dari jalur data dan diperlukan untuk membantu memastikan proses transfer data tetap berjalan stabil dan baik.

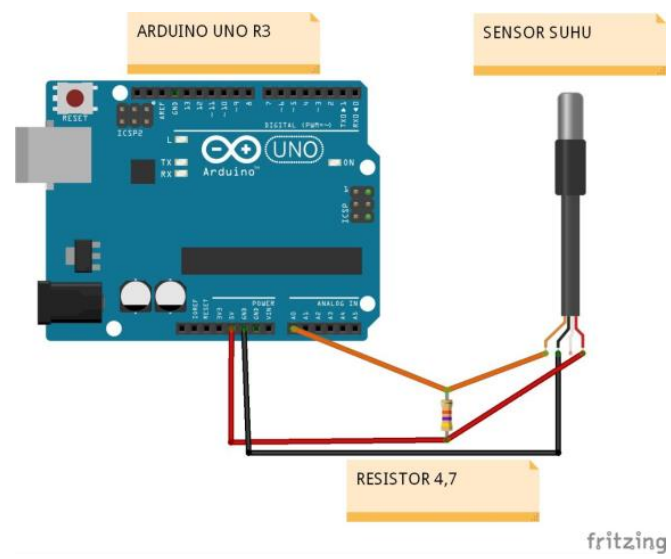

Gambar 4. Perancangan Sensor Suhu DS18b20 dan Resistor

Perancangan PH meter, PH meter adalah sebuah alat elektronik yang berfungsi untuk mengukur $\mathrm{pH}$ (derajat keasaman atau kebasaan) suatu cairan (ada elektroda khusus yang berfungsi untuk mengukur $\mathrm{pH}$ bahan-bahan semi padat) [12]. Sebuah $\mathrm{pH}$ meter terdiri dari sebuah elektroda (probe pengukur) yang terhubung ke sebuah alat elektronik yang mengukur dan menampilkan nilai $\mathrm{pH}$. alat ini sangat berguna untuk mengukur kejernihan air pada akuarium.

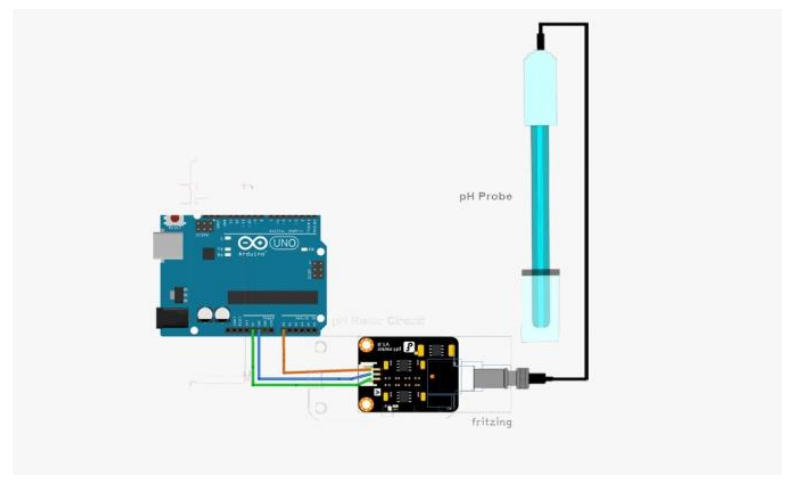

Gambar 5. Skematik Perancangan $\mathrm{pH}$ meter

Perancangan LCD, Modul Liquid Crystal Display (LCD) ini merupakan modul display yang serbaguna, karena dapat digunakan untuk menampilkan berbagai tampilan baik berupa huruf, angka dan karakter lainnya serta dapat menampilkan berbagai macam tulisan maupun pesan-pesan pendek lainnya. Di perancangan alat ini, LCD digunakan untuk menampilkan waktu kapan pompa OFF dan kapan pompa OFF secara real time.

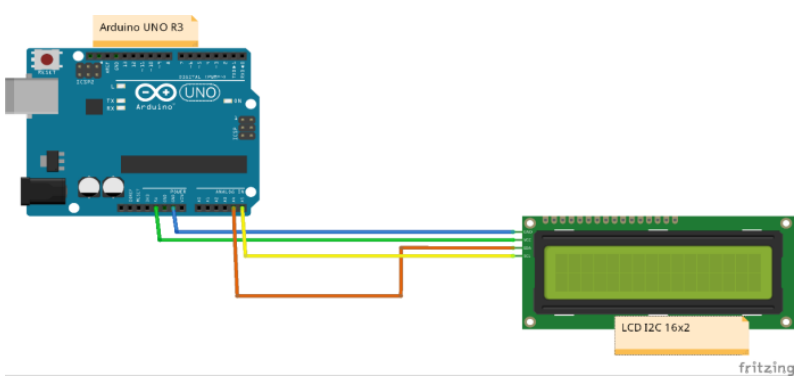

Gambar 6. Skematik Perancangan LCD

d. Perancangan sistem

Perancangan sistem pada software Arduino sangat lah penting sebab dari sinilah program dibuat dan diupload mengunakansoftware Arduino, hal ini bertujuan untuk menyisipkan kode program kedalam Arduino

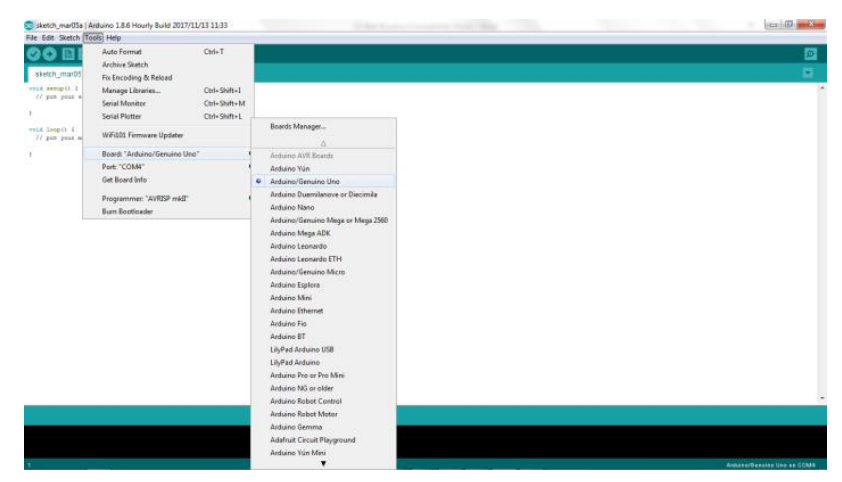

Gambar 7. Inisisalisasi Jenis Arduino Pada IDE Arduino

Langkah ini bertujuan untuk memilih jenis dari mikrokontroller Arduino yang akan digunakan untuk membuat sistem. Pada perancangan alat ini menggunkan Arduino Uno R3. Selain langkah di atas kita juga perlu menginisialkan Port Serial tujuannya agar Arduino dapat terhubung ke komputer biasanya mengunakan sebuah kabel USB agar Arduino dapat terhubung dengan komputer [13][14]. Berikut ini adalah contoh penginisialan Port Arduino pada Softaware IDE Arduino.

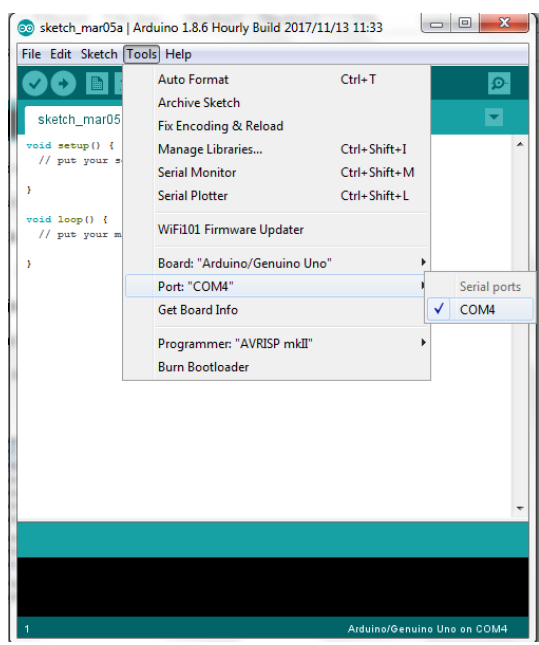

Gambar 8. inisialisasi port serialArduino. 
e. Penulisan Kode Program

Penulisan kode program dilakukan untuk memberikan instruksi-instruksi mengunkan bahasa pemrograman $\mathrm{C}$ yang bertujuan untuk menjalankan sistem agar dapat berkerja sesuai kode program yang telah diisikan kedalam sebuah Arduino, tanpa kode program sistem tidak dapat berkerja sebab kode program adalah bagian yang paling utama dalam kita membuat sebuah alat. Berikut ini adalah tampilan layer untuk mengisikan kode program pada Software.

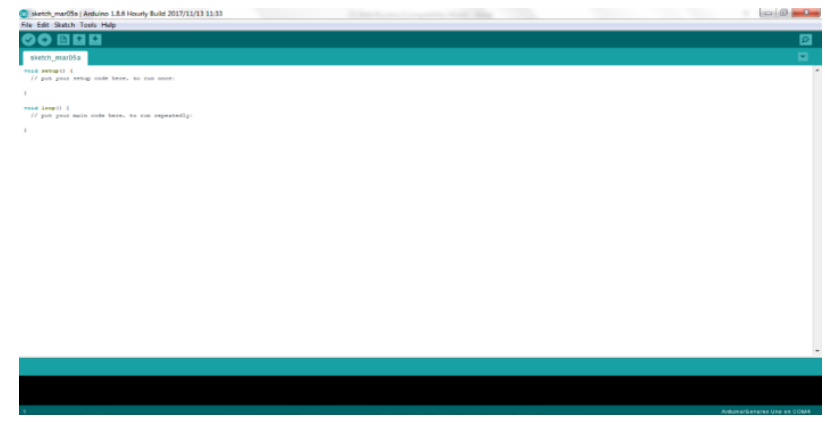

Gambar 9 Layer Penulisan Sketch Program

Implementasi Sistem Melakukan implementsi dan pembanguan sistem sebagai penyelesaian masalah, Tujuan pengujian Mikrokontroler pada alat ini yaitu untuk menentukan apakah alat yang telah dibuat telah berfungsi dengan baik dan sudah sesuai dengan perancangan atau belum. Pengujian pada alat ini meiputi pengujian setiap blok maupun pengujian secara keseluruhan. Pengujian setiap blok ini dilakukan untuk menentukan letak kesalahan dan mempermudah dalam analisa mikrokontroler bila alat tidak bekerja sesuai rancangan.

\section{Pengujian Komponen}

Dalam pengujian komponen akan dibahas tentang pengujian berdasarkan perencanaan dari mikrokontroler yang dibuat dan pengujian yang dilakukan sesuai dengan perencanaan yang dibahas. Mula-mula pengujian dilakukan dengan terpisah, mulai dari komponen-komponen yang digunakan dalam perancangan alat ini sehingga mendapatkan hasil yang diinginkan. Setelah itu pengujian dilanjutkan dengan pengujian dari keseluruhan rangkaian komponen mikrokontroler yang telah terpasang. Pengujian yang akan dilakukan adalah Pengujian sesnor $\mathrm{pH}$ air,Pengujian sensor suhu DS18b20, Pengujian LCD $16 \times 2$

a. Pengujian Sensor $\mathrm{pH}$ Air Pengujian sensor $\mathrm{pH}$ air ini merupakan proses perhitungan $\mathrm{pH}$ air yang hanya mengandalkan sensor ini. Sensor $\mathrm{pH}$ air menggunakan sinyal analog sebagai transimisinya. Rentang dari sinyal analog ini terdiri dari 10 bit dengan rentang 0-1023. Perlu diketahui bahwa nilai yang dikeluarkan oleh sensor merupakan nilai ADC (Analog to Digital Converter) yang akan diproses lebih lanjut. Pengujian ini dilakukan untuk membuktikan apakah sensor dapat bekerja dengan baik atau tidak.

b. Pengujian sensor suhu air ini merupakan proses perhitungan sensor suhu air yang hanya mengandalkan sensor ini. Pengujian ini dilakukan untuk membuktikan apakah sensor dapat bekerja dengan baik atau tidak. Pada tahap ini dilakukan pengujian terhadap sampel air yang ada di media aquarium.

c. Pengujian LCD 16x2 Pada tahap ini adalah pengujian komunikasi mikrokontroler arduino dengan LCD 16x2, pada alat ini LCD 16x2 digunakan sebagai monitor untuk mengetahui kondisi kerja sistem pemantauan lebih mudah.

\section{Kesimpulan}

Berdasarkan pembahasan dan hasil dari penelitian, maka diperoleh beberapa kesimpulan sebagai berikut :

1. Dengan melihat hasil dari pembacaan sensor $\mathrm{pH}$ air, maka petani dapat menentukan bahwa air tersebut dalam keadaan baik atau tidak untuk tanaman sawi. Hasil dari pembacaan sensor $\mathrm{pH}$ air memiliki selisih yang tidak begitu jauh dengan $\mathrm{pH}$ meter yaitu 5.5 sampai 6.5.

2. Hasil pembacaan sensor Suhu air sudah bekerja dengan baik dan akan mengirim data ke arduino untuk ditampilkan ke layar LCD.

3. Hasil tanaman pada aquaponik sangat bagus, karena menggunakan pupuk dari kotoran ikan yang ada pada aquaponik.

\section{Saran}

Adapun saran-saran yang dapat dipertimbangkan dari hasil penelitian ini agar penelitian ini dapat dikembangkan lebih lanjut yaitu:

1. Untuk penggunaan sensor $\mathrm{pH}$ air ini diharapkan penelitian selanjutnya dapat memilih sensor yang memiliki kualitas lebih bagus lagi, dikarenakan sensor yang saat ini digunakan masih kurang baik dan terkadang masih kurang stabil dalam pembacaan.

2. Diharakan untuk penelitian selanjutnya dapat menggunakan sensor - sensor lainnya, seperti sensor kejernihan air dan sensor lainnya.

\section{Daftar Pustaka}

[1] Tn Huda, 2017 Latar Belakang Aquaponik. URL : http://eprints.polsri.ac.id/4661/2/File\%202.pdf

[2] A. Nurkholis, A. Riyantomo dan M. Tafrikan, "Sistem pakar penyakit lambung menggunakan metode forward chaining," Majalah Ilmiah Momentum, vol. 13, no. 1, 2017.

[3] A. Nurkholis, dan I. S. Sitanggang, "Optimalisasi model prediksi kesesuaian lahan kelapa sawit menggunakan algoritme pohon keputusan spasial," 
Jurnal Teknologi dan Sistem Komputer, vol. 8, no. 3, pp. 192-200, Jul. 2020.

[4] M Vahlefi, 2015 Latar belakang Aquaponik. URL:http:/eprints.polsri.ac.id/2754/2/BAB\%20I.pdf

[5] A Hidayat, 2017. Permen Kesehatan, No. 416/Men.Kes/PER/IX/1990 tentang Syarat-syarat dan Pengawasan Kualitas Air. URL : https://www.slideshare.net/infosanitasi/per-menkes416-90syaratsyarat-dan-pengawasan-kualitas-air.

[6] D. Alita, S. Priyanta dan N Rokhmn., "Analysis Emoticon and Sarcasm Effect on Sentiment Analysis of Indonesian Language in Twitter",JISEBI, 2019.

[7] Alita, D., Fernando, Y., \& Sulistiani, H. (2020). IMPLEMENTASI ALGORITMA MULTICLASS SVM PADA OPINI PUBLIK BERBAHASA INDONESIA DI TWITTER. Jurnal Tekno Kompak, 14(2), 86-91.

[8] S. Samsugi dan A. Burlian, "Sistem penjadwalan pompa air otomatis pada aquaponik menggunakan mikrokontrol Arduino UNO R3," Prosiding Semnastek, vol. 1, no. 1, 2019.

[9] I. K. Gunawan, A. Nurkholis dan A. Sucipto, "Sistem monitoring kelembaban gabah padi berbasis Arduino," Jurnal Teknik dan Sistem Komputer, vol. 1, no. 1, pp. 1-7, 2020.

[10] A.E. Kumala, R.I. Borman dan P. Prasetyawan, "Sistem Informasi Monitoring Perkembangan Sapi Di Lokasi Uji Performance (Studi Kasus: Dinas Peternakan Dan Kesehatan Hewan Provinsi Lampung)," Jurnal Tekno Kompak, Vol. 12, No. 1, pp.5-9, 2018.
[11]D.E. Kurniawan, M. Iqbal, J. Friadi, R.I. Borman dan R. Rinaldi. "Smart Monitoring Temperature and Humidity of the Room Server Using Raspberry Pi and Whatsapp Notifications," In Journal of Physics: Conference Series (Vol. 1351, No. 1, p. 012006) IOP Publishing, 2019.

[12]S. Samsugi, Ardiansyah dan A. Suwantoro, "Pemanfaatan Peltier dan Heater Sebagai Alat Pengontrol Suhu Air Pada Bak Penetasan Telur Ikan Gurame," Conference on Information Technology, Information System and Electrical Engineering, pp. 295-299, 2016.

[13] K. Pindrayana, R.I. Borman, B. Prasetyo dan S. Samsugi, "Prototipe Pemandu Parkir Mobil Dengan Output Suara Manusia Mengunakan Mikrokontroler Arduino Uno," CIRCUIT: Jurnal Ilmiah Pendidikan Teknik Elektro, vol. 2, no. 2, 2018.

[14] S. Samsugi dan D.E. Silaban, "Purwarupa Controlling Box Pembersih Wortel Dengan Mikrokontroler," Prosiding Nasional Rekayasa Teknologi Industri dan Informasi XIII, pp. 1-7, 2018. 